\title{
The French human Salmonella surveillance system: evaluation of timeliness of laboratory reporting and factors associated with delays, 2007 to 2011
}

G Jones (gabrielle.jones@ars.sante.fr) ${ }^{1}, \mathbf{S}$ Le Hello ${ }^{2}$, N Jourdan-da Silva $^{1}$, V Vaillant $^{1}$, H de Valk ${ }^{1}$, F X Weill ${ }^{2}$, Y Le Strat $^{1}$

1. French Institute for Public Health Surveillance (Institut de Veille Sanitaire, InVS), Saint-Maurice, France

2. Institut Pasteur, National Reference centre for Salmonella, Paris, France

Given the regular occurrence of salmonellosis outbreaks in France, evaluating the timeliness of laboratory reporting is critical for maintaining an effective surveillance system. Laboratory-confirmed human cases of Salmonella infection from whom strains were isolated from 2007 to 2011 in France $(n=38,413)$ were extracted from the surveillance database. Three delay intervals were defined: transport delay (strain isolation, transport from primary laboratory to national reference laboratory), analysis delay (serotyping, reporting) and total reporting delay. We calculated the median delay in days and generated the cumulative delay distribution for each interval. Variables were tested for an association with reporting delay using a multivariable generalised linear model. The median transport and analysis delays were 7 and 6 days respectively (interquartile range (IQR: 6-10 and 4-9 respectively), with a median total reporting delay of 14 days (IQR: 11-19). Timeliness was influenced by various external factors: decreasing serotype frequency, geographical zone of primary laboratory and strain isolation on Sundays were the variables most strongly associated with increased length of delay. The effect of season and day of the week of isolation was highly variable over the study period. Several areas for interventions to shorten delays are identified and discussed for both transport and analysis delays.

\section{Introduction}

A primary aim of infectious disease surveillance is to detect changes in disease incidence in order to mount an appropriate public health response [1]. There are inherent delays in surveillance between symptom onset and reporting to health agencies, and the reporting chain consists of multiple steps at which delays can accumulate [2].

In France, the human Salmonella surveillance system is a voluntary laboratory-based network headed by the National Reference Centre for Salmonella (NRC) based at the Pasteur Institute in Paris. Participating laboratories (1,392/2,253 (62\%) in 2011) send around 8,000 Salmonella isolates to the NRC per year. The NRC performs serotyping analysis and runs weekly outbreak detection algorithms, notifying exceeded thresholds to the French Institute for Public Health Surveillance (Institut de Veille Sanitaire, InVS) [3]. The NRC also signals in real time to the InVS any suspected clusters based on observations of serotyping results in the course of their analysis. During outbreaks, serotyping results are notified to the InVS in real time. In 2008, it was estimated that the Salmonella surveillance system detected $66 \%$ of laboratory-confirmed human Salmonella infections in France [4].

Reporting timeliness reflects the speed with which a case of a reportable disease passes through each stage in the reporting chain from symptom onset to reporting to health authorities and is a key component of any disease surveillance system [5]. For Salmonella, which is a consistent source of outbreaks in France (representing 92 of 210 laboratory confirmed food-borne outbreaks (44\%) in 2010) [6], rapid detection of clusters is a critical element of an outbreak investigation. Every day gained from timely reporting of cases can aid health authorities in leading an investigation that can identify the source of contamination and control the spread of illness (Figure 1). Therefore, regularly evaluating the timeliness of surveillance systems is crucial for maintaining an effective system $[7,8]$.

Previous timeliness studies have been conducted for a number of countries and reportable diseases, including salmonellosis, but no standardised method has been established [1,7,9-11]. The impact of individual factors, such as reporting method (paper or electronic), has been studied $[12,13]$; however, the effect of multiple factors, including those related to the structure of the surveillance system (primary laboratory type and location) or to the disease in question (seasonality, serotype), has not been explored. Identifying areas for improvement would allow for targeted efforts to 


\section{FIGURE 1}

Effect of early detection and response to an outbreak on the number of cases observed: standard scenario (A) and early detection scenario (B)

A. Standard scenario

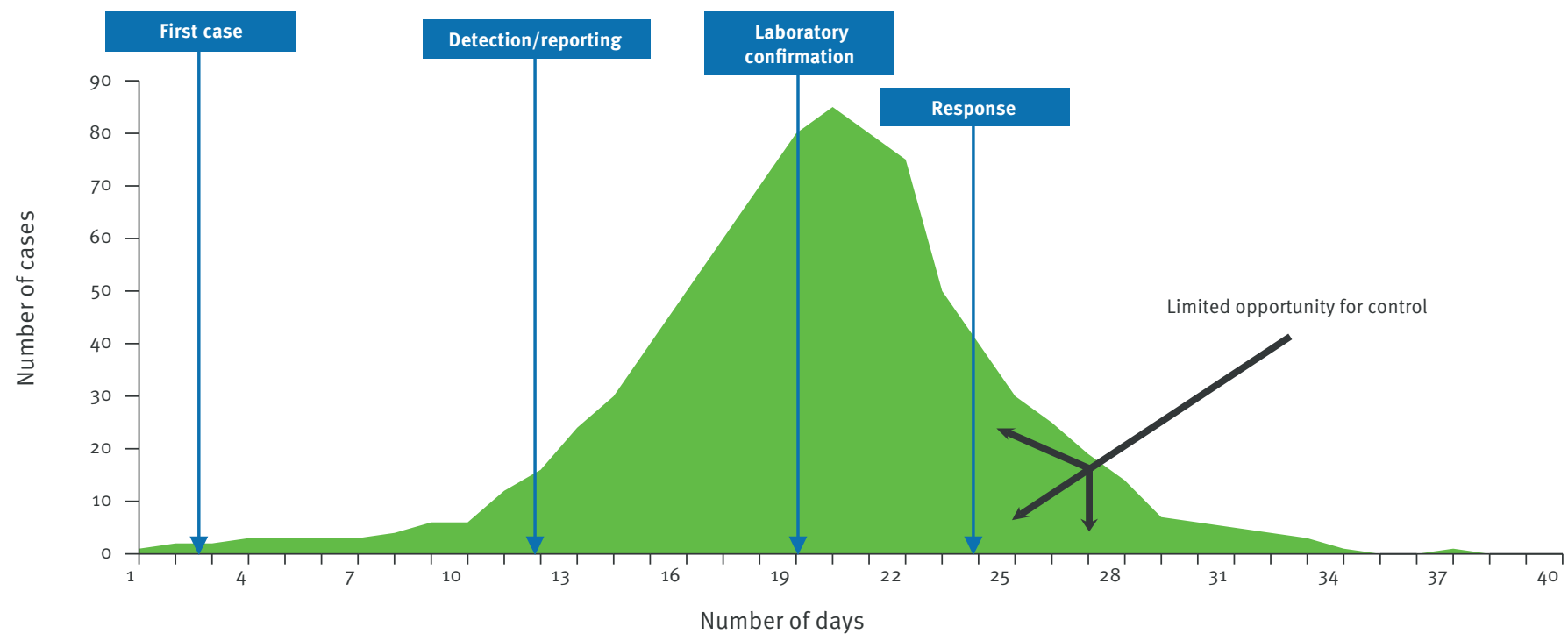

B. Early detection scenario

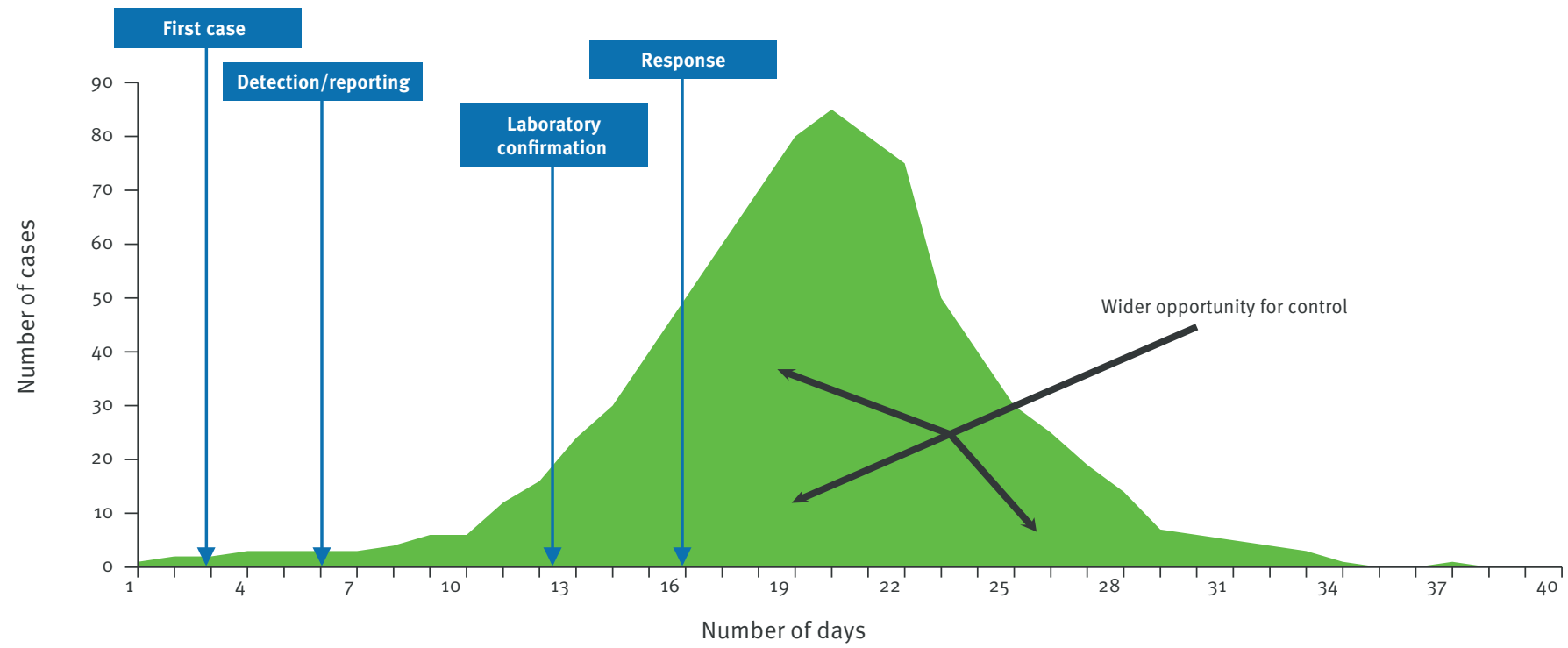

Cases preceding the 'first case' represent a baseline of cases that may occur sporadically.

reduce delays. Furthermore, the information obtained on reporting delays could be integrated into methods of prediction or estimation of cases that are based on historic data [14].

As Salmonella surveillance in France is based on a voluntary laboratory network coordinated by the NRC, delays can occur at two levels: (i) at the primary laboratory (strain isolation and transport to the NRC) and (ii) at the NRC (serotyping and transmission of the results to InVS). The aim of this study is to assess the timeliness of the French human Salmonella surveillance system, to identify factors associated with reporting delays and to identify opportunities to shorten these delays.

\section{Methods}

The NRC extracted from the Salmonella surveillance database the case number, serotype, specimen type, isolation date at primary laboratory, date of reception at NRC, date of validation (serotyping report available to InVS), reporting year, primary laboratory type and 
Stages in the reporting chain and delay intervals for human Salmonella surveillance in France
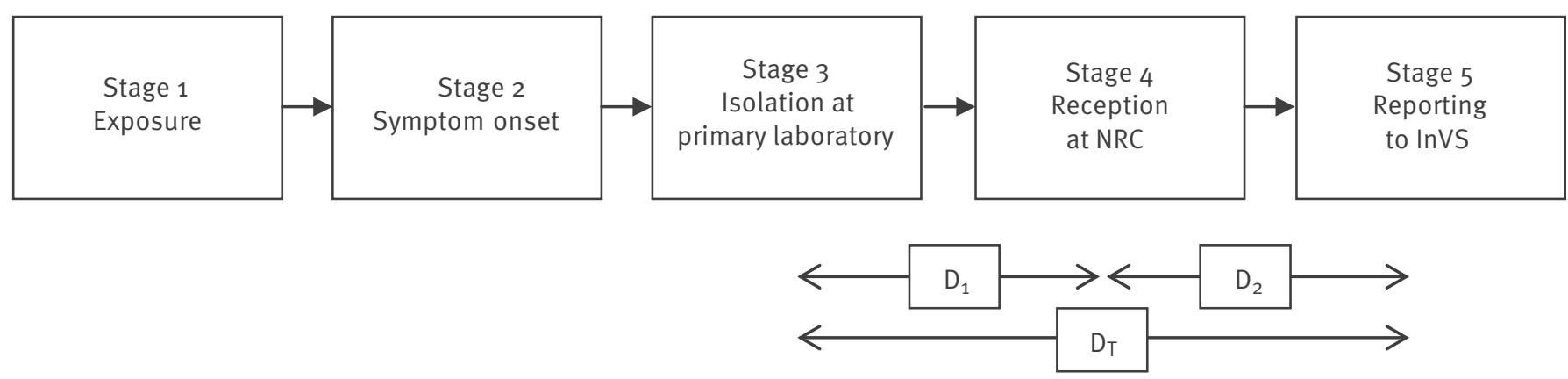

$\mathrm{D}_{1}$ : transport delay

$\mathrm{D}_{2}$ : analysis delay

$\mathrm{D}_{\mathrm{T}}$ : total reporting delay

InVS: French Institute for Public Health Surveillance (Institut de Veille Sanitaire); NRC: National Reference Centre for Salmonella.

laboratory and patient postal codes. We generated additional variables from the data including serotype frequency, whether the serotype was a monophasic variant of Typhimurium, geographical zone of the primary laboratory, season of reception of isolates at the $\mathrm{NRC}$, isolation year and day of the week of isolation at primary laboratory. The study period included strains isolated from 1 January 2007 to 31 December 2011.

\section{Reporting delays}

We defined five stages in the reporting chain (Figure 2). Exposure date (stage 1) is only available from outbreak investigations for which a specific source or exposure is known. Date of symptom onset (stage 2) is not routinely collected by the surveillance system. Surveillance data included dates associated with stages 3, 4 and 5, permitting the calculation of three delay intervals: transport delay $\left(D_{1}\right)$ from strain isolation at the primary laboratory to reception at the NRC (partial serotyping for certain primary laboratories and transport of the sample), analysis delay $\left(D_{2}\right)$ from reception at the NRC to serotyping report available to InVS (serotyping and transmission of results) and total reporting delay $\left(D_{T}\right)$ from strain isolation to the serotyping report being available to InVS. If one of these dates was missing, only the delay interval for which both dates were available was calculated.

Timeliness was evaluated based on the observed delays for the three delay intervals for each isolate in the database. Incoherent dates and aberrant delays were identified and verified. The median delay of each interval was calculated along with the interquartile range (IQR). The empirical cumulative delay distribution, $F(t)$, was generated, as this represents delays better than other indicators such as the mean, which is influenced by extreme values, or the median, which may mask differences occurring before or after the $50 \%$ point.
To analyse factors associated with reporting delays, eight variables were selected from the available data: (i) type of primary laboratory of strain isolation (private or hospital); (ii) season of isolate reception at the NRC; (iii) specimen type (blood, stool or other); (iv) serotype frequency (number of isolates received at the NRC in 2011: very frequent (200), frequent (53-200), fairly frequent (12-52), rare ( 12$)$ ); (v) monophasic variant of Typhimurium 1,4,[5],12:i:- (yes or no); (vi) isolation year; (vii) geographical zone of primary laboratory (Paris, North, West, East, South, South-west, South-east and overseas); and (viii) day of the week of strain isolation at primary laboratory (day of week). Monophasic variants of Typhimurium were selected due to recent emergence, their initially time-consuming typing protocol and placement as the second most-frequent serotype in France [4]. The cumulative delay distributions were plotted for selected variables and statistical analyses carried out to determine the variables significantly associated with reporting delays.

\section{Statistical analyses}

We used a regression model based on the method proposed by Brookmeyer and Liao [15] for comparison of the cumulative delay distributions. We conducted univariable analysis ( $p<0.05$ ) followed by multivariable analysis using a generalised linear model (GLM) with the complementary log-log link function. A threshold of p 0.05 was selected due to the large number of isolates (good statistical power). Analyses were conducted using Stata version 11 (StataCorp LP, College Station, TX, United States). A detailed description of the statistical analyses used is included at the end of the article.

\section{Results}

A total of 38,413 Salmonella strains were isolated from January 2007 to December 2011. Of these, 1,619 (4.2\%) were excluded before analysis (multiple dates missing, 
Median total reporting delay in the French human Salmonella surveillance system in days by sampling month, 2007-2011

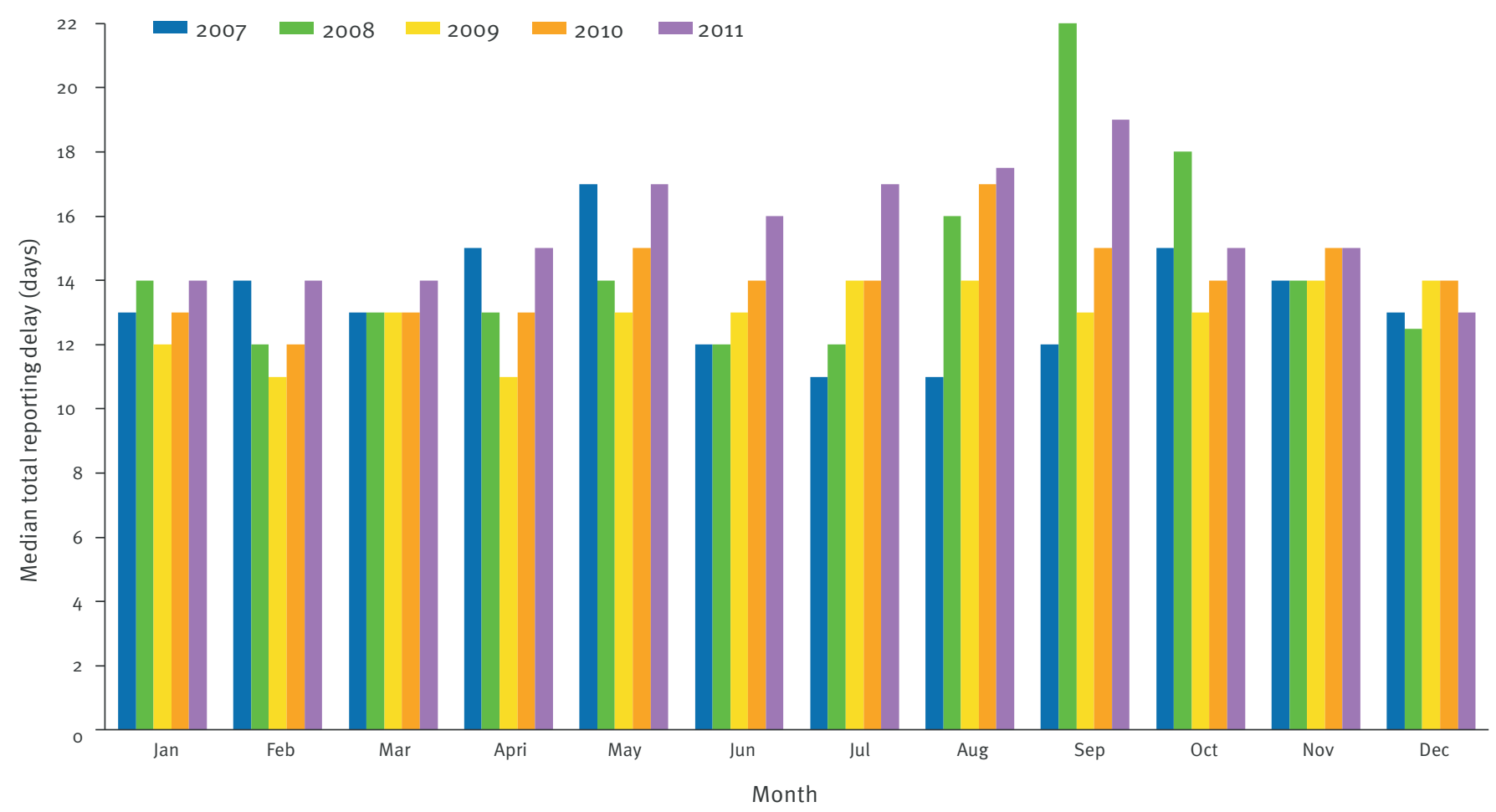

sample originating from laboratories overseas that do not regularly participate in surveillance). For the remaining isolates $(n=36,794)$, it was possible to calculate the transport delay $\left(D_{1}\right)$ for 35,450 isolates (96\%), the analysis delay $\left(D_{2}\right)$ for 36,630 isolates (99\%) and the total reporting delay $\left(D_{T}\right)$ for 35,287 isolates ( $\left.96 \%\right)$.

The median transport delay was 7 days (IQR: 6-10), the median analysis delay 6 days (IQR: 4-9) and the median total reporting delay 14 days (IQR: 11-19) with intra- and inter-year variability observed for monthly median delays. The median total reporting delay by month ranged from a minimum of 11 days to a maximum of 22 days over the study period (Figure 3). Variability was observed between years, with intrayear differences of as little as 3 days to as many as 10 days between months.

\section{Comparison of cumulative delay distributions}

The cumulative delay distribution represents at time $t$ the probability that the reporting delay is less than or equal to $t$. Figure 4 compares the distribution of the three delay intervals for delays from 0 to 60 days. A higher curve indicates shorter delays relative to a lower curve.

Visual comparison of the cumulative delay distributions for the transport delay $\left(D_{1}\right)$ and the analysis delay $\left(D_{2}\right)$ reveals a disproportionate effect of certain variables on these delay intervals. The variables for which the transport delay distributions were most

\section{FIGURE 4}

Cumulative delay distribution of transport delay $\left(D_{1}\right)$, analysis delay $\left(\mathrm{D}_{2}\right)$ and total reporting delay $\left(\mathrm{D}_{\mathrm{T}}\right)^{\mathrm{a}}$, French human Salmonella surveillance system, 2007-2011

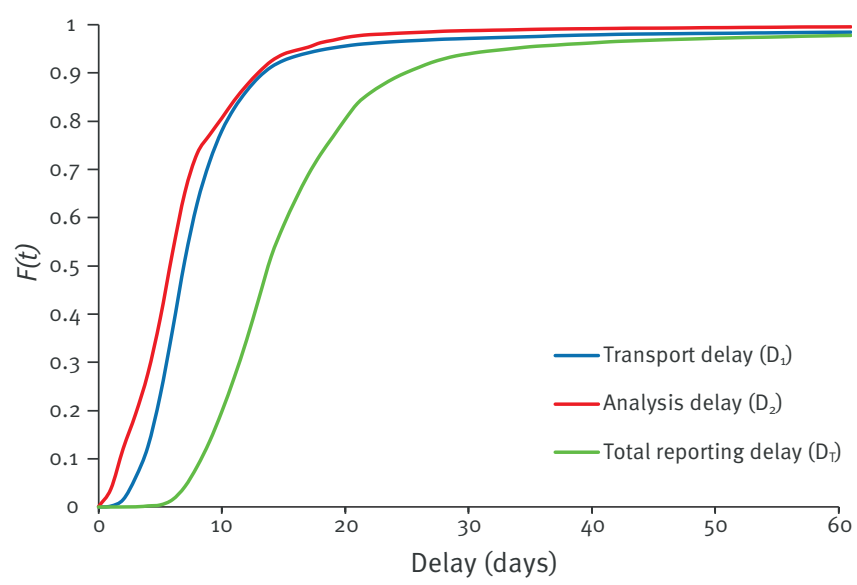

$F(t)$ : empirical cumulative delay distribution.

A cut-off of 60 days was used for clarity of graphical representation as more than $95 \%$ of isolates were received at the National Reference Centre for Salmonella and/or reported to the French Institute for Public Health Surveillance (Institut de Veille Sanitaire, InVS) within this time period.

a For delays from o to 60 days. 
Cumulative delay distributions ${ }^{a}$ for transport and analysis delays, French human Salmonella surveillance system, 2007-2011

A. Transport delay by primary laboratory type

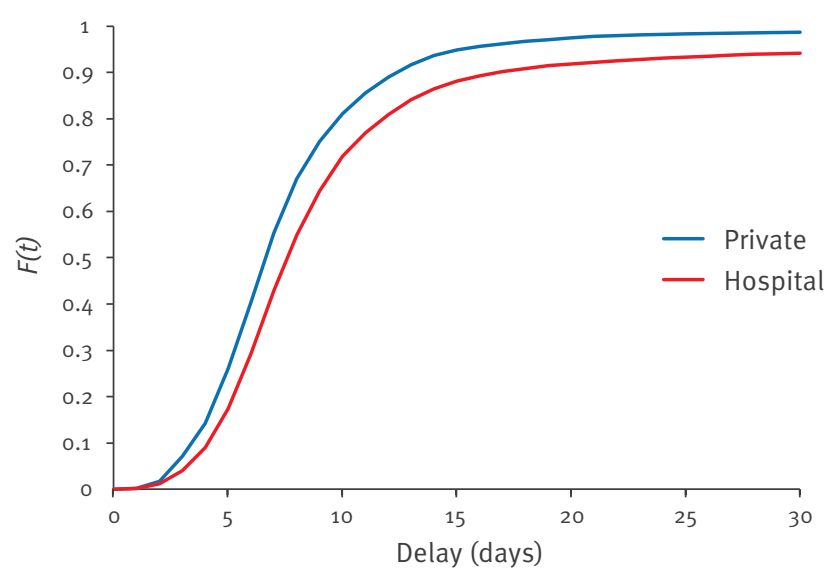

C. Analysis delay by season of reception at the NRC

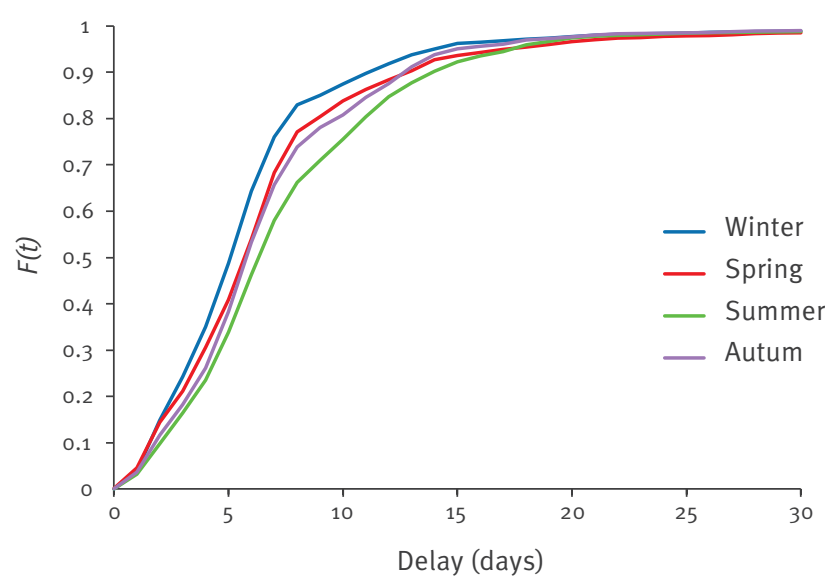

B. Transport delay by geographical zone of primary laboratory

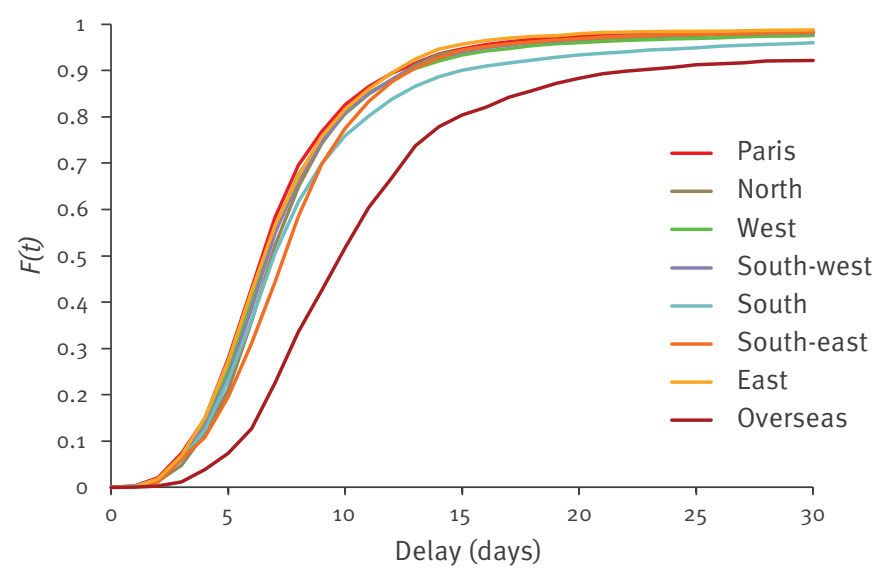

D. Analysis delay by by serotype frequency ${ }^{b}$

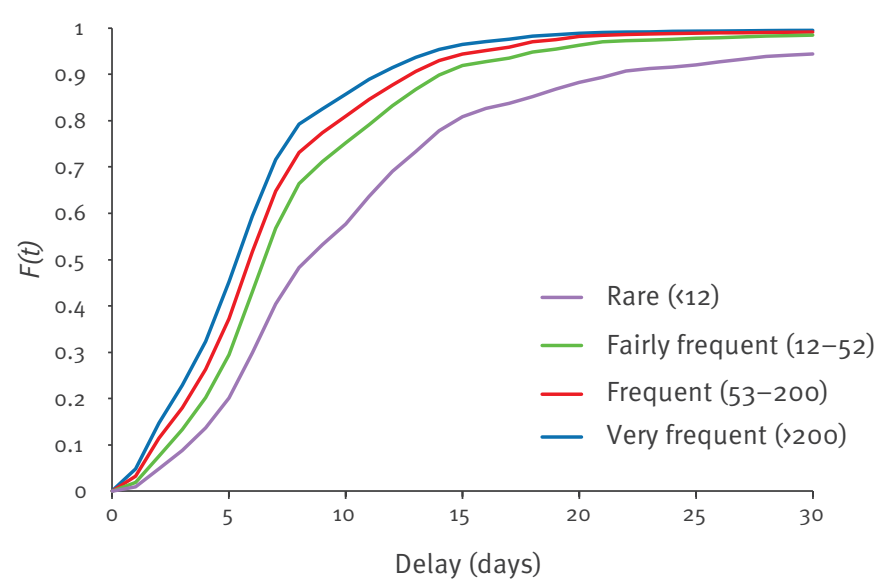

$F(t)$ : empirical cumulative delay distribution; NRC: National Reference Centre for Salmonella.

A cut-off of 30 days was used for clarity of graphical representation as more than $95 \%$ of isolates were received at the National Reference Centre for Salmonella and/or reported to the French Institute for Public Health Surveillance (Institut de Veille Sanitaire, InVS) within this time period.

a For delays from o to 30 days.

b Number of isolates received at the NRC in 2011.

greatly influenced were laboratory type (Figure $5 \mathrm{a}$ ) and geographical zone of primary laboratory (Figure $5 \mathrm{~b}$ ). Hospital laboratories had a greater transport delay than private laboratories, as did laboratories overseas relative to those in mainland France. Day of the week of strain isolation also influenced $D_{1}$, but the grouping of the distribution curves prevented further interpretation (data not shown).

Conversely, season (Figure $5 c$ ) and serotype frequency (Figure $5 \mathrm{~d}$ ) showed the greatest degree of divergence for the analysis delay distributions. The analysis delay increased with decreasing serotype frequency and seasonal trends showed the shortest delays in winter and the longest delays in summer.

Delays for both $D_{1}$ and $D_{2}$ differed by isolation year, but no trends were observed, indicating that these delays did not increase or decrease consistently over the fiveyear study period (data not shown). Specimen type and monophasic variants of Typhimurium showed little difference in their effect on $D_{1}$ and $D_{2}$ (data not shown). 
TABLE

Association between variables and total reporting delay using a multivariable generalised linear model and stratified by isolation year, French human Salmonella surveillance system, 2007-2011

\begin{tabular}{|c|c|c|c|c|c|c|c|c|c|c|}
\hline & \multicolumn{2}{|c|}{2007} & \multicolumn{2}{|c|}{2008} & \multicolumn{2}{|c|}{2009} & \multicolumn{2}{|c|}{2010} & \multicolumn{2}{|c|}{2011} \\
\hline & $\hat{\beta}$ & SE & $\hat{\beta}$ & SE & $\hat{\beta}$ & SE & $\hat{\beta}$ & SE & $\hat{\beta}$ & SE \\
\hline \multicolumn{11}{|l|}{ Laboratory type } \\
\hline Private & ref & ref & ref & ref & ref & ref & ref & ref & ref & ref \\
\hline Hospital & $0.352^{\star \star \star}$ & 0.035 & $0.411^{\star \star \star}$ & 0.030 & $0.421^{\star \star \star}$ & 0.031 & $0.349^{\star \star *}$ & 0.030 & $0.295^{\star \star \star}$ & 0.027 \\
\hline \multicolumn{11}{|c|}{ Monophasic variant of Typhimurium } \\
\hline No & ref & ref & ref & ref & ref & ref & ref & ref & ref & ref \\
\hline Yes & $1.965^{\star \star *}$ & 0.111 & $1.477^{\star \star \star}$ & 0.060 & $0.797^{\star \star \star}$ & 0.040 & $0.423^{\star \star \star}$ & 0.039 & $0.104^{\star \star \star}$ & 0.029 \\
\hline \multicolumn{11}{|c|}{ Serotype frequency } \\
\hline Very frequent & ref & ref & ref & ref & ref & ref & ref & ref & ref & ref \\
\hline Frequent & $0.726^{* \star *}$ & 0.044 & $0.822^{\star \star \star}$ & 0.040 & $0.440 * \star \star$ & 0.038 & $0.421^{\star \star *}$ & 0.036 & $0.440 * \star \star$ & 0.035 \\
\hline Fairly frequent & $0.869^{\star \star \star}$ & 0.046 & $0.754^{\star \star \star}$ & 0.038 & $0.668^{\star * \star}$ & 0.040 & $0.556^{\star \star \star}$ & 0.037 & $0.666^{\star \star \star}$ & 0.037 \\
\hline \multicolumn{11}{|c|}{ Geographical zone } \\
\hline Paris & ref & ref & ref & ref & ref & ref & ref & ref & ref & ref \\
\hline North & $0.712^{\star \star \star}$ & 0.071 & $0.577^{\star \star \star}$ & 0.060 & $0.786^{\star \star \star}$ & 0.065 & $0.613^{\star \star \star}$ & 0.060 & $0.702^{\star \star \star}$ & 0.062 \\
\hline West & $0.334^{\star * \star}$ & 0.051 & $0.144^{\star \star}$ & 0.043 & $0.185^{\star \star *}$ & 0.046 & $0.153^{\star * \star}$ & 0.043 & $0.153^{\star \star \star}$ & 0.041 \\
\hline South-west & $0.288^{* * *}$ & 0.050 & $0.178^{\star \star \star}$ & 0.044 & $0.239^{\star \star \star}$ & 0.046 & $0.177^{\star \star \star}$ & 0.044 & $0.115^{\star \star}$ & 0.040 \\
\hline South & $0.450 * \star \star$ & 0.055 & $0.416^{\star \star \star}$ & 0.049 & $0.314^{\star \star \star}$ & 0.049 & $0.384^{* \star \star}$ & 0.051 & $0.282^{\star \star \star}$ & 0.043 \\
\hline South-east & $0.136 * *$ & 0.052 & $0.149^{\star \star \star}$ & 0.042 & $0.209^{\star \star \star}$ & 0.041 & $0.248^{\star \star \star}$ & 0.041 & $0.223^{\star \star \star}$ & 0.039 \\
\hline East & $0.336^{\star * \star}$ & 0.057 & $0.337^{\star \star \star}$ & 0.050 & $0.258^{\star \star \star}$ & 0.051 & $0.330^{\star \star *}$ & 0.050 & $0.288^{\star \star \star}$ & 0.046 \\
\hline Overseas & $0.783^{\star \star \star}$ & 0.072 & $0.971^{\star \star \star}$ & 0.076 & $0.829^{\star \star \star}$ & 0.066 & $0.569^{\star \star \star}$ & 0.060 & $0.631^{* \star *}$ & 0.058 \\
\hline \multicolumn{11}{|c|}{ Season of isolate reception at NRC } \\
\hline Summer & ref & ref & ref & ref & ref & ref & ref & ref & ref & ref \\
\hline Spring & $0.547^{\star \star \star}$ & 0.043 & $-0.123^{\star \star}$ & 0.038 & -0.020 & 0.035 & 0.048 & 0.034 & 0.001 & 0.031 \\
\hline Autumn & $0.566^{\star \star \star}$ & 0.043 & -0.026 & 0.034 & $0.155^{\star \star \star}$ & 0.034 & -0.036 & 0.032 & $-0.381^{\star \star \star}$ & 0.030 \\
\hline \multicolumn{11}{|c|}{ Day of the week of strain isolation } \\
\hline Monday & ref & ref & ref & ref & ref & ref & ref & ref & ref & ref \\
\hline Tuesday & 0.052 & 0.053 & -0.077 & 0.045 & 0.053 & 0.045 & -0.040 & 0.044 & $0.138^{\star \star \star}$ & 0.040 \\
\hline Wednesday & 0.102 & 0.054 & 0.070 & 0.046 & $0.186^{\star \star \star}$ & 0.046 & 0.000 & 0.045 & $0.130 * \star$ & 0.040 \\
\hline Thursday & 0.088 & 0.053 & 0.044 & 0.047 & $0.128^{\star \star}$ & 0.046 & 0.051 & 0.046 & $0.232^{\star \star \star}$ & 0.040 \\
\hline Friday & $0.167^{\star \star}$ & 0.055 & 0.066 & 0.046 & $0.159^{\star \star}$ & 0.048 & 0.039 & 0.045 & $0.157^{\star \star \star}$ & 0.040 \\
\hline Saturday & $0.163^{* *}$ & 0.057 & 0.061 & 0.049 & $0.188^{* \star *}$ & 0.049 & 0.071 & 0.048 & $0.149^{\star \star \star}$ & 0.043 \\
\hline Sunday & $0.639^{\star \star \star}$ & 0.082 & $0.324^{\star \star \star}$ & 0.061 & $0.415^{\star \star \star}$ & 0.062 & $0.452^{\star \star \star}$ & 0.068 & $0.463^{\star \star \star}$ & 0.058 \\
\hline
\end{tabular}

NRC: National Reference Centre for Salmonella; ref: reference; SE: standard error.

* $\mathrm{p}<0.05$

** $p<0.01$

*** p<0.001

$\hat{\beta}$ is a regression coefficient adjusted on other coefficients (not shown) representing reporting delays grouped into time intervals. 
For the total reporting delay, $\mathrm{D}_{\mathrm{T}}$, the variables having the greatest influence on delays were primary laboratory type, serotype frequency, season, geographical zone of primary laboratory and isolation year. The influence of these variables on the individual delay intervals $D_{1}$ and $D_{2}$ were reflected in the cumulative delay distributions of the total reporting delay.

Analyses of variables associated

with reporting delays

Results of the multivariable model for the association between six variables (significant in univariable analysis) and the total reporting delay are shown in the Table. The analysis was stratified by isolation year due to its statistically significant interactions with season of isolate reception at the NRC and day of week the strain was isolated ( $p<0.05$ ).

The association between reporting delays and most variables remained significant for the entire study period. The coefficient $\hat{\beta}$ represents the effect on $a$ delay by a given variable and adjusted for all other variables in the model. A positive $\hat{\beta}$ value represents a longer delay and a negative $\hat{\beta}$ value a shorter delay. The force of the association is shown by the relative $\hat{\beta}$ value. All geographical zones had significantly longer delays than Paris, but the overseas and North zones exhibited consistently longer delays and the force of the association was similar. Hospital laboratories had longer delays than private laboratories and the association was relatively stable over time. Similarly, the association between serotype frequency and reporting delays was maintained, with delays increasing as serotype frequency decreased. A trend was observed for monophasic variants of Typhimurium, with reporting delays for such variants consistently longer than for non-monophasic variants, but this decreased sharply from $\hat{\beta}=1.965$ in 2007 to $\hat{\beta}=0.104$ in 2011 .

Two variables, season and day of week, stood out. The effect of these variables on the total reporting delay fluctuated over the study period. Only samples isolated on Sunday had consistently longer delays than those isolated other days (largest $\hat{\beta}$ value). Otherwise, the associations between these variables and shorter or longer delays ranged from statistically significant one year to non-significant the next, with no trends over time.

\section{Discussion and conclusions}

In this first study of laboratory reporting timeliness of human Salmonella surveillance in France, we identified key intervals in the reporting chain and calculated the associated delays. Direct international comparison of timeliness for Salmonella reporting is difficult due to differences in the structure of public health and surveillance systems (e.g. mandatory vs voluntary reporting, steps in the reporting chain). The delay intervals described in our study are solely laboratory related, while previous studies in the United States and Europe included a greater number of intervals from symptom onset to reporting to health authorities $[8,10,13,16]$. One study in Ireland allows direct comparison: the transport and analysis delays we identified in France of 7 and 6 days respectively are longer than those reported in 2008 in Ireland for the equivalent intervals (4 and 5 days respectively) [7].

In this study, the emergence of the monophasic variant of Typhimurium 1,4,[5],12:i:- (not expressing the 1,2 phase) followed by a better knowledge of the clone and improved analysis techniques, is evident. Longer delays were observed at the beginning of the study period (due to, for example, multiple confirmatory analyses carried out by testing several colonies, the use of polymerase chain reaction and sequencing to identify the $f l j B$ gene encoding the 1,2 antigen), followed by a sharp decrease as the lack of this second phase was more readily recognised and such techniques were no longer used [17]. Thus, by 2011 these variants no longer represented one of the strongest factors in increased reporting delays. This trend was most pronounced for the analysis delay, but was also observed for the transport delay.

Trends related to the transport delay can be explained in part by two factors: the structure of the laboratory network in different geographical zones (laboratories may refer their isolates to hospital or specialised laboratories for transport) and the capacity of laboratories to perform partial serotyping before the isolate is sent to the NRC. The analysis performed was able to identify a systematic difference in the delays for samples originating from the overseas and North zones, information that can be used to target efforts to decrease delays related to the primary laboratories in these zones.

Trends related to the analysis delay, notably the increase in delay with decreasing serotype frequency, can be associated in part to factors associated with the analysis protocol at the NRC (verification of serotyping results for rare serotypes) [18].

The variables season and day of week demonstrate the inconsistent effect of certain factors on reporting delays over time. The NRC in France adapts its staff availability to Salmonella seasonality by assigning all technicians to serotyping in the summer in an effort to minimise backlogs; however, personnel turnover or large outbreaks during peak vacation periods (when there are fewer personnel) may still result in increased delays in some years. An example was observed clearly in September 2008 (Figure 3), where a large peak in delays coincided with personnel turnover in the preceding months and a backlog in the NRC analysis. Limited staffing situations may be a risk for increased delays, with an immediate observable effect. Such information should be taken into account in the current public health context in which budget restrictions render such conditions more and more common. 
This study has several limitations. First, the surveillance system does not collect the date of symptom onset and therefore the delays in the reporting chain from symptom onset to strain isolation at the primary laboratory cannot be systematically evaluated. The date of symptom onset can be obtained from case interviews in outbreak investigations and an analysis of 16 investigations at the InVS from 2007 to 2011 containing the date of symptom onset showed a median delay from date of symptom onset to strain isolation at the primary laboratory of 4 days (unpublished data). This delay was shorter than the 7 days observed in studies on Salmonella reporting timeliness in both the United States and Ireland $[7,10]$. In addition, the median delay between symptom onset and strain isolation differed between hospital laboratories (3 days) and private laboratories ( 5 days). The information gained from the cases for whom date of symptom onset was available highlights the value of including such information in surveillance data, which would allow for more complete timeliness evaluation.

Second, information regarding protocols at the primary laboratories is limited. Delays incurred by factors - such as transportation service (large services with daily collection vs small services with less frequent collection) or partial serotyping (use of a limited number of antisera to identify the most prevalent serotypes) before sending the isolate to the NRC - cannot be fully evaluated. A 2008 study of 3,217 medical laboratories in France found that $35 \%$ of laboratories performed partial serotyping of Salmonella isolates (65\% hospital laboratories vs $31 \%$ private laboratories) [19]. Partial serotyping allows more rapid clinical results and orientation of patient treatment (non-typhoidal vs typhoidal salmonellosis), but may also increase the transport delay for isolates difficult to type at the primary laboratory. These additional delays may affect surveillance and delay detection of clusters by the NRC.

For Salmonella surveillance, it is critical that delays are as short as possible in order to rapidly detect outbreaks, to monitor their progression and to assess the impact of control measures. In outbreak detection and investigation, every day gained in early detection counts since the implementation of control measures may avoid additional cases. The delay until detection varies widely between outbreaks and depends on characteristics of the outbreak, the algorithm used and reporting delays. The characteristics of the outbreak (e.g. sudden increase or prolonged onset, serotype frequency, proportion of sporadic cases) cannot be influenced and there is little opportunity to decrease detection delay. It is possible to reduce the detection delay by setting lower thresholds in the algorithm. However, this will decrease the specificity of cluster detection and lead to a potentially large number of false alerts. Currently, the delay between the identification of the outbreak and notification to the InVS is less than one day. Therefore, efforts to reduce the detection delay should focus on the reporting delays.
In this study, we were able to analyse timeliness of laboratory-based surveillance of human Salmonella over a five-year period as the system remained unchanged. Timeliness of Salmonella reporting in France depends on a number of variables that intervene along the reporting chain. These factors can be distinguished by their effect on the transport delay or conversely on the analysis delay at the NRC. Both the transport and the analysis delay demonstrate potential for improvement through targeted measures. For example, time can be gained by encouraging immediate transport of samples to the NRC, by efficient serotyping or by more frequent running of algorithms. Additionally, the implementation of a web-based system for real-time reporting of partial serotyping results (scheduled for implementation in 2014) would permit the NRC to rapidly obtain serotype information from laboratories before submission of the actual isolate. Such a system would provide pertinent real-time information about cases not yet received by the NRC that may serve to alert the NRC to potential clusters or to supplement data during alerts.

For human Salmonella surveillance in France, obtaining information regarding primary laboratory protocols should be encouraged as part of the surveillance network and efforts to increase awareness for timely submission of isolates should be emphasised in order to decrease the transport delay, particularly in certain geographical zones. On the basis of the results of this study, we recommend that participating laboratories be requested to transport a sample of any Salmonella isolate immediately to the NRC before partial serotying. While laboratories could continue to perform partial serotyping to orient clinical treatment, simultaneously sending a sample to the NRC could serve to reduce the delays incurred by waiting for the results of partial serotying before sample submission.

Current efforts to minimise delays at the NCR focus on assigning all technicians to serotyping during the summer to coincide with seasonality. However, from a technical standpoint, changes in serotyping methods could also be considered, to reduce the analysis delay. Notably, molecular methods could replace the classic serotyping by agglutination currently used at the NRC (White-Kauffmann-Le Minor scheme [18]). Achtman et al. recently evaluated multilocus sequence typing (MLST) for Salmonella, finding it a suitable alternative to classic serotyping [20]. It is likely that as costs of molecular methods continue to decrease, such methods can feasibly be adopted by the NRC to decrease the analysis delay.

The fluctuating association between delays and the variables season, monophasic variants of Typhimurium and day of the week demonstrate the potential instability of delays over time. Therefore, timeliness of the surveillance system should be regularly evaluated to target areas for improvement and to determine if implemented changes have been effective. Furthermore, 
methods of prediction or estimation based on reporting delays from historical data should be mindful of hypotheses regarding the stability of delays over time.

This study proposes a new method for the evaluation of timeliness of laboratory reporting for Salmonella surveillance and for identifying factors impacting reporting delays. It can be adapted for any infectious disease surveillance system. A better understanding of reporting delays and associated variables is essential for optimising disease surveillance systems and maximising their capacity to mount an appropriate and effective public health response.

\section{Additional information: statistical analyses}

We used a regression model for comparison of the cumulative delay distributions. According to the method proposed by Brookmeyer and Liao [15], isolates were grouped by sampling month and then categorised by reporting delay into $m$ index periods of finite values in days designated $t_{1}, \ldots, t_{m}$. For each $j=1, \ldots m$, the number of isolates per sampling month reported at time $t_{j}$ was designated $Y_{j}$ and the total number of isolates with a reporting delay less than or equal to $t_{j}$ was designated $n_{j}$. In order to represent the reporting delays for Salmonella isolates, a nonparametric estimate of the cumulative delay distribution, $F(t)$, was used. $F(t)$ can be expressed as the product of conditional probabilities, $p_{i}$, which represents the probability that the reporting delay is equal to $t_{j}$ given that the delay is less than or equal to $t_{j}$. The estimate of the conditional probability can be expressed as $p j=Y_{j} / n_{j}$ and the estimate of the cumulative delay distribution:

$$
\hat{F}\left(t_{s}\right)=\prod_{j=s+1}^{m}\left(1-\frac{Y_{j}}{n_{j}}\right) s=1, \ldots, m-1
$$

The above method is particularly useful as it is adaptable for analysis of multiple variables. The database of isolates can be stratified into $\mathrm{K}$ strata, which are generated by crossing variables of interest present in the database. The notation in the previous paragraph is extended using the subscript $\mathrm{k}$ to index the strata $\left(p_{j k}\right.$ is the conditional probability at time $t_{j}$ in the stratum $k$ ).

A GLM with the complementary log-log link function was chosen as it provides the following relationship between the dependent variable (here the conditional probability of reporting within time t) and the explicative variables $\mathrm{Xk}$ :

$$
\log \left(-\log \left(1-p_{j k}\right)\right)=\alpha_{j}+\beta X_{k}
$$

where $a_{j}$ and $\beta=\left(\beta_{1}, \ldots, \beta_{q}\right)$ are the regression parameters. The association between variables and the total reporting delay, adjusted for the covariables in the model, is represented by the estimate of the parameter $\beta$. Interpretation of the coefficient $\beta_{q}$ associated with the covariable $x_{q}$ is as follows: a positive $\beta q$ represents a longer delay for increasing values of $x_{q}$, while a negative $\beta_{q}$ indicates a shorter delay with increasing values of $x_{q}$.

\section{References}

1. Reijn E, Swaan CM, Kretzschmar MEE, van Steenbergen JE. Analysis of timeliness of infectious disease reporting in the Netherlands. BMC Public Health. 2011;11:409. http://dx.doi.org/10.1186/1471-2458-11-409 PMid:21624131 PMCid:PMC3141442

2. Allos BM, Moore MR, Griffin PM, Tauxe RV. Surveillance for sporadic foodborne disease in the 21st century: the FoodNet perspective. Clin Infect Dis. 2004;38 Suppl 3:S115-20. http://dx.doi.org/10.1086/381577 PMid:15095179

3. Weill FX, Le Hello S. Centre National de Référence des Salmonella: rapport d'activité annuel 2011. [National Reference Center for Salmonella: Annual activity report 2011]. Paris: Institut Pasteur; 2011. French. Available from: http://www. pasteur.fr/ip/resource/filecenter/document/01S-00004j-03v/ ra-cnr-salm-2011.pdf

4. Jourdan-Da Silva N, Le Hello S. Salmonelloses en France, 2002-2010: tendances en épidémiologie humaine, émergence de la souche monophasique, principaux aliments impliqués dans les dernières épidémies. [Salmonellosis in 2002-2010 in France: trends in human epidemiology, monophasic serotype emergence, main food implicated in the latest outbreaks]. Bulletin Epidémiologique Hebdomadaire Hors-série. 9 May 2012;25-8. Available from: http://opac.invs.sante.fr/doc_num. php?explnum_id $=8148$

5. German RR, Lee LM, Horan JM, Milstein RL, Pertowski CA, Waller MN, et al. Updated guidelines for evaluating public health surveillance systems: recommendations from the Guidelines Working Group. MMWR Recomm Rep. 2001;50(RR13):1-35.

PMid:18634202

6. Institut de Veille Sanitaire (InVS). Surveillance des toxi-infections alimentaires collectives: données de la déclaration obligatoire, 2010. [Surveillance of food-borne outbreaks: Mandatory reporting data, 2010]. Paris: InVS; 2011. Available from: http://www.invs.sante.fr/Dossiers thematiques/Maladies-infectieuses/Risques-infectieux-dorigine-alimentaire/Toxi-infections-alimentaires-collectives/ Donnees-epidemiologiques

7. Nicolay N, Garvey P, Delappe N, Cormican M, McKeown P. Completeness and timeliness of Salmonella notifications in Ireland in 2008: a cross sectional study. BMC Public Health. 2010;10:568.

http://dx.doi.org/10.1186/1471-2458-10-568 PMid:20860803 PMCid:PMC 2955005

8. Jajosky RA, Groseclose SL. Evaluation of reporting timeliness of public health suveillance systems for infectious diseases. BMC Public Health. 2004;4:29.

http://dx.doi.org/10.1186/1471-2458-4-29

PMid:15274746 PMCid:PMC509250

9. Altmann M, Spode A, Altmann D, Wadl M, Benzler J, Eckmanns T, et al. Timeliness of surveillance during outbreak of Shiga toxin-producing Escherichia coli Infection, Germany, 2011. Emerg Infect Dis. 2011;17(10):1906-9. http://dx.doi.org/10.3201/eid1710.111027 PMid:22000368 PMCid:PMC3310688

10. Hedberg CW, Greenblatt JF, Matyas BT, Lemmings J, Sharp DJ, Skibicki RT, et al. Timeliness of enteric disease surveillance in 6 US states. Emerg Infect Dis. 2008;14(2):311-3.

http://dx.doi.org/10.3201/eid1402.070666

PMid:18258128 PMCid:PMC2600210

11. Yoo HS, Park O, Park HK, Lee EG, Jeong EK, Lee JK, et al. Timeliness of national notifiable diseases surveillance system in Korea: a cross-sectional study. BMC Public Health. 2009;9:93.

http://dx.doi.org/10.1186/1471-2458-9-93

PMid:19331696 PMCid:PMC2676269

12. Ward M, Brandsema $P$, van Straten E, Bosman A. Electronic reporting improves timeliness and completeness of infectious disease notification, The Netherlands, 2003. Euro Surveill. 2005;10(1):pii=513. Available from: http://www. eurosurveillance.org/ViewArticle.aspx?Articleld $=513$

13. Centers for Disease Control and Prevention (CDC). Potential effects of electronic laboratory reporting on improving timeliness of infectious disease notification--Florida, 20022006. MMWR Morb Mortal Wkly Rep. 2008;57(49):1325-8. PMid:19078921 
14. Donker T, van Boven M, van Ballegooijen WM, Van't Klooster TM, Wielders CC, Wallinga J. Nowcasting pandemic influenza A $\mathrm{H}_{1} \mathrm{~N}_{1} 2009$ hospitalizations in the Netherlands. Eur J Epidemiol. 2011;26(3):195-201.

http://dx.doi.org/10.1007/s10654-011-9566-5

PMid:21416274 PMCid:PMC3079092

15. Brookmeyer R, Liao JG. The analysis of delays in disease reporting: methods and results for the acquired immunodeficiency syndrome. Am J Epidemiol. 1990;132(2):35565. PMid:2372012

16. Kirk MD, Dalton CB, Beers M, Cameron AS, Murray C.

Timeliness of Salmonella notifications in South Australia. Aust N Z J Public Health. 1999;23(2):198-200

http://dx.doi.org/10.1111/j.1467-842X.1999.tbo1235.x PMid:10330738

17. Hopkins KL, Kirchner M, Guerra B, Granier SA, Lucarelli C, Porrero MC, et al. Multiresistant Salmonella enterica serovar 4,[5],12:i:- in Europe: a new pandemic strain? Euro Surveill. 2010;15(22):pii=19580. Available from: http://www. eurosurveillance.org/ViewArticle.aspx?Articleld $=19580$ PMid:20546690

18. Grimont PA, Weill FX. Antigenic formulae of the Salmonella serovars. 9th ed. Paris: World Health Organization Collaborating Centre for Reference and Research on Salmonella, Institut Pasteur; 2007. Available from: http:// www.pasteur.fr/ip/portal/action/WebdriveActionEvent/ oid/015-000036-089

19. Carillo-Santisteve P, Jourdan-da Silva N, Le Hello S, Letort MJ, Fromage M, Weill FX. Completeness and representativity of the Salmonella voluntary survaillance system in France, 2008. In: Abstract book. ESCAIDE. European Scientific Conference on Applied Infectious Disease Epidemiology. Lisbon, 11-13 November 2010. Stockholm: European Centre for Disease Prevention and Control; 2010. Abstract available from: http:// ecdc.europa.eu/en/ESCAIDE/Documents/ESCAIDE2010_ abstract book.pdf\#page $=61$

20. Achtman M, Wain J, Weill FX, Nair S, Zhou Z, Sangal V, et al. Multilocus sequence typing as a replacement for serotyping in Salmonella enterica. PLoS Pathog. 2012;8(6):e1002776. http://dx.doi.org/10.1371/journal.ppat.1002776 PMid:22737074 PMCid:PMC3380943 